\title{
DISTRACTION EXTERNAL FIXATIONS OF PELVIC FRACTURES CAUSED BY A LATERAL COMPRESSION
}

\author{
Pavlin Apostolov, Martin Burnev, Petar Milkov \\ Clinic of Orthopaedics and Traumatology \\ MBAL "Saint Anna” Hospital - Varna, Bulgaria
}

\begin{abstract}
:
The authors represent a distraction external pelvic fixation technique, which they use in pelvic fractures caused by a lateral compression. They consider the indications and mounting techniques. The authors recommend the early movement activities (on the $3^{\text {rd }}-5^{\text {th }}$ day) after the external fixator placement. This method had been used in 8 patients and 3 cases are analyzed in details. The priority of this technique over open reduction and internal fixation (ORIF) mainly are: (1) the implementation of good reduction of the fracture preventing the risk of ORIF; (2) the possibility for early movement activities for the patient.
\end{abstract}

Key words: Pelvic Fractures; External Fixator; Distraction Technique

\section{INTRODUCTION:}

Most authors treat these injuries with bed rest and symptomatic therapy. We share the opinion of Bellabarba et al. ${ }^{4}$ that there are fractures of this type with which surgical treatment can be applied, using closed reduction and maintenance of the distraction with a supra-acetabular external fixator, followed by immediate weight bearing. We consider this a highly effective, relatively simple, and minimally invasive method with which there is a minimal blood loss and the patient can be rapidly mobilized. We apply distraction external fixation if there is more than 1.5 $\mathrm{cm}$ overlap of the fracture lines (or after a reduction of the so-called "locked" symphysis). We also maintain this with women who intend to give birth the normal way but the existing deformation would prevent it (in cases of bone lesions that do not affect the symphysis and SI joints). There is a certain risk for the posterior pelvic ring to be destabilized and a hemorrhage to be provoked during the reduction. For this reason, we usually maintain it after the $5^{\text {th }}$ to $7^{\text {th }}$ day. According to Tile, reduction is advocated in regard to young patients with a significant deformation and functional limb length discrepancy of more than $2 \mathrm{~cm}^{5}$

MATERIALS AND METHODS:

We applied the present technique (April 2006 - April
2011) in 8 cases ( 6 female and 2 male). In all cases, the anterior fixation was with a supra-acetabular external fixator. Posterior stabilization was as follows: 6 cases - by plate, 1 case - by an exterior fixator, 1 case - "reverse" traverse. The traverse is called "reverse" when the fixing nuts are placed from the inside of the iliac bone, in order to oppose the compression component of the fracture.

We would also like to mention a more uncommon pelvic fracture of lateral-compression type - the so-called Tilt fracture also referring to as Type - B2.1 by M. Tile. This is an injury of the anterior pelvic ring, which is usually underestimated and conservatively treated. In Orthopaedics and Traumatology Journal $\left(2005,4^{\text {th }}\right.$ ed.), we (Apostolov, P. et al.) recommended its more active surgical treatment to avoid its complications - subluxation and early arthrosis when the fracture engages the anterior column of the acetabulum and the development of dispareunia with women. The diagnosis for a Tilt fracture is radiographical and it is best seen on the inlet view (it is often missed only on AP), CT scan, and 3D. KT is compulsory in order to avoid injury in the posterior pelvic part - most commonly a compression fracture of the sacrum (impaction), typical for most B2 lesions.

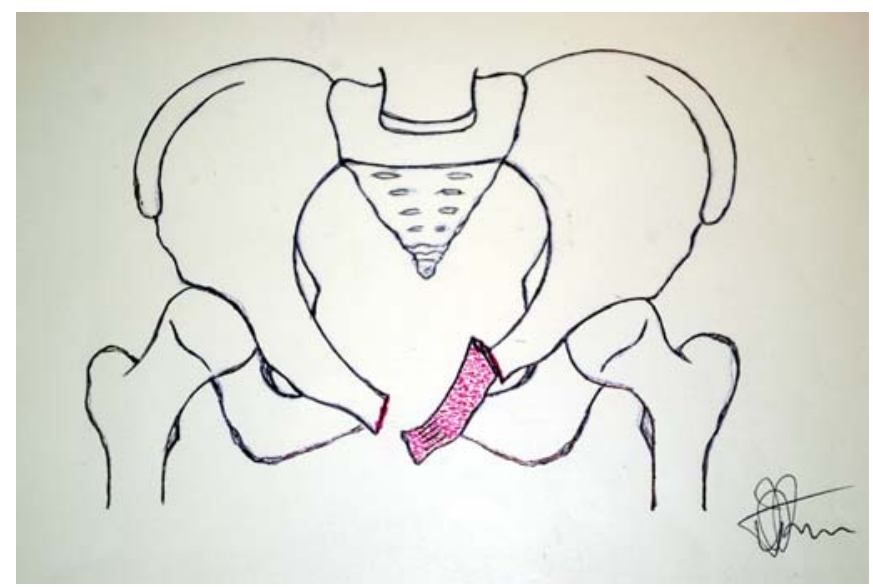

Fig. 1a 


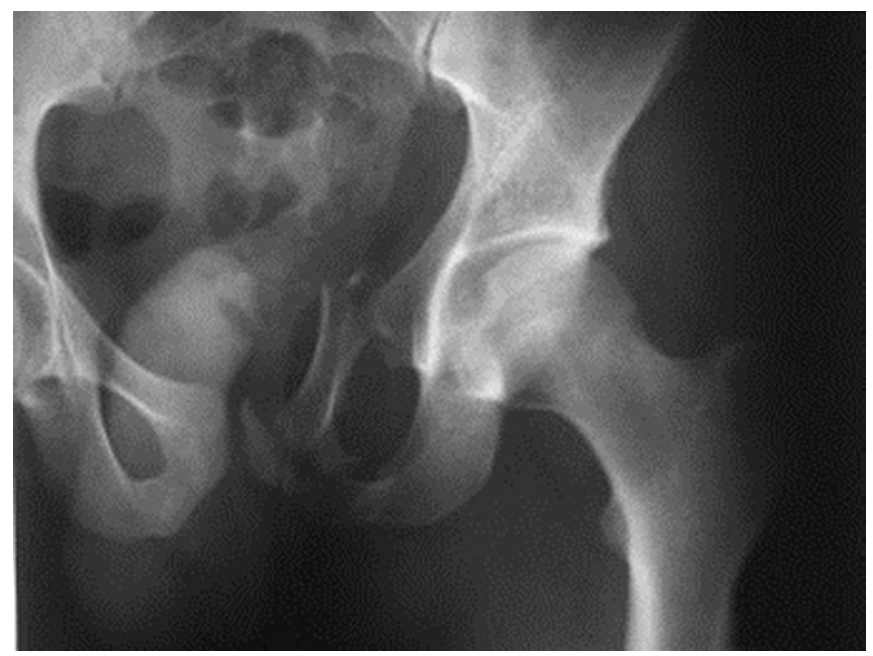

Fig. 1b

Zingi calls this fracture "closed book tilt fracturedislocation". He defines 3 different levels of injury severity in B2.1, corresponding to 3 degrees of instability:

- Fracture of the two rami

- Symphyseal overlapping

- Tilt-fracture

We offered our classification of the tilt-fractures:

- Type 1 - extra articular (without affecting the anterior acetabulum column)

- Type 2 - intra articular (affecting the anterior column)

When there is a dislocation of more than $1 \mathrm{~cm}$ (especially with young women) in type 1 , and $3 \mathrm{~mm}$ in type 2 , we recommend surgical treatment. In some appropriate cases, we start the treatment conservatively - by an attempt of reduction with the patient being on his back, on a radiotransparent table under X-ray monitoring. An external rotation of the hip is maintained with a flexed knee and a direct pressure on the fragment. In case of success, an exterior fixator is placed with a mild external rotation (distraction) of the hemipelvis to maintain the reduction, and to reduce the stress in the anterior part. We are extremely careful, if there is an incomplete compression fracture of the sacrum. Burgess and Tile, in this case, recommend a very cautious reduction, so that to avoid a complete fracture of the sacrum and thus a C-type injury (total instability). ${ }^{5,6} \mathrm{In}$ case of a successful closed reduction, the fragment can be fixed with a half-pin, intramedullary (or a K-wire), placing an external fixator as well. The pin insertion is followed on inlet and outlet-obturator view, which will best prevent us from penetration in the acetabulum or entering the region of the vascular lacuna. If the closed method is unsuccessful, then we should approach for an open reduction.

\section{DISCUSSION:}

Distraction external fixation is also applied with injuries of the posterior part of the pelvic ring - for example with transforaminal sacrum fractures, in which there are obliteration or narrowing of the canals with more than $\mathrm{S}$ (CT), with or without neurological symptoms, that need neurological decompression.

We consider the distraction technique highly appropriate for its simplicity, ease, and high maintenance speed, as well as for the possibility to allow the patient's early rising and loading. We recommend the anterior fixation to be maintained by a supra-acetabular fixation, because of its proved priorities.

\section{Case 1:}

V.S.S. - nineteen-year-old, after a road traffic accident, pelvic fracture (ossis pubis, ossis sacri - anterior impact). Partial (minor) return of the deformation is observed prior to the fixator removal. However, the functional result is excellent.

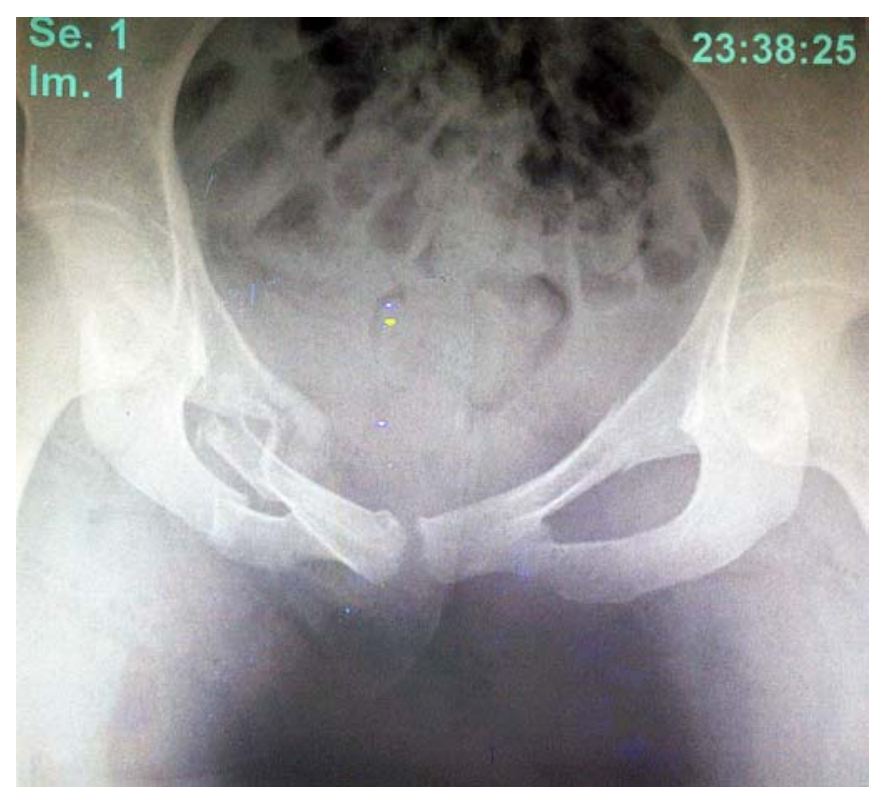

Fig. 2a. 

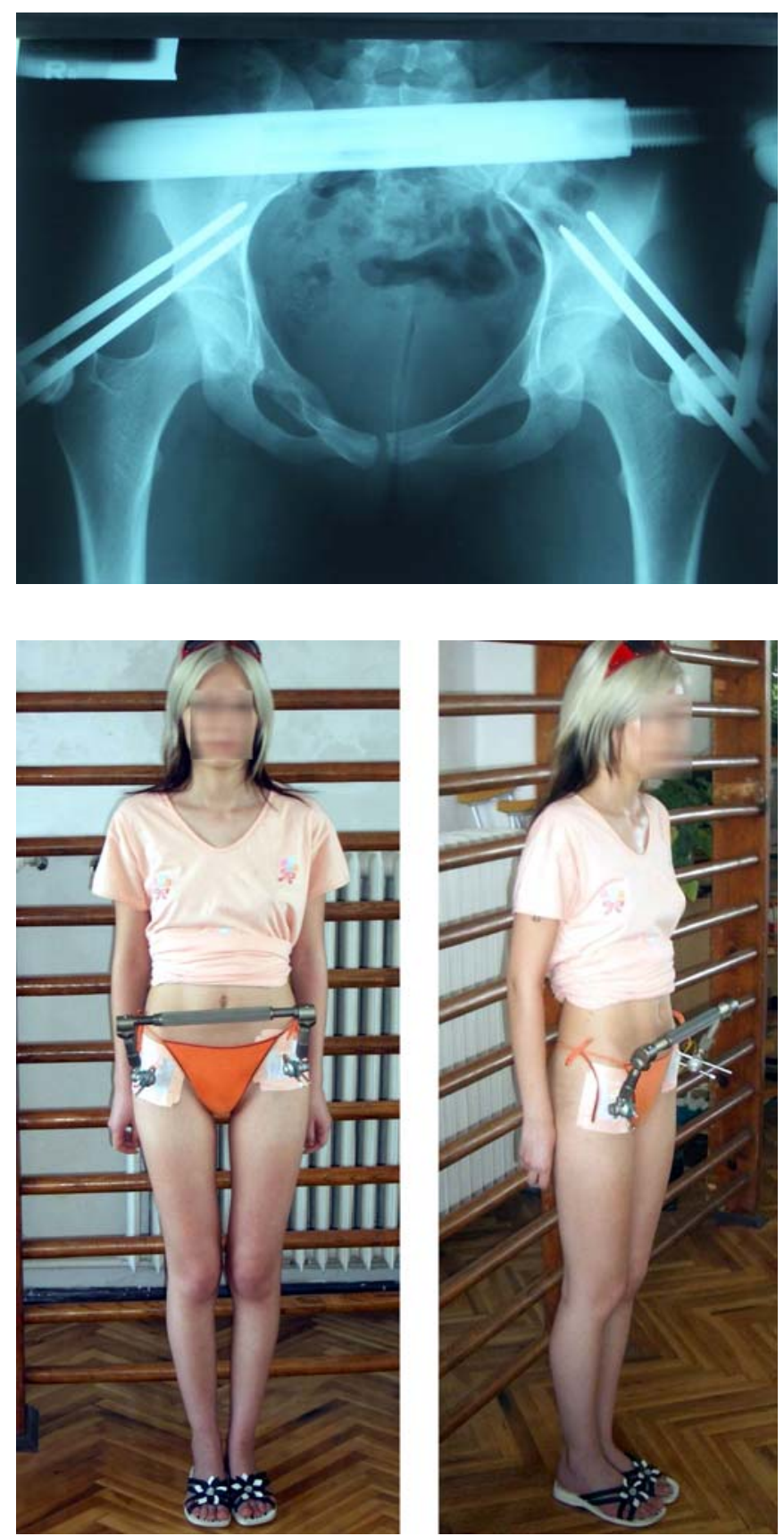

Fig. 2-b, 2-c, 2-d.

On the control radiographology, on the $30^{\text {th }}$ day, we saw a partial return of the dislocation - probably due to the $200 \mathrm{~km}$ transportation of the patient to her home. On the $60^{\text {th }}$ day, there was not any additional dislocation and the patient was walking independently with the fixator, without any assistive devices.

Case 2: D. J. - 23-year-old, after a road traffic accident, LC-injury (with dislocation and overlapping of the pubis arms $>3 \mathrm{~cm}$ ):

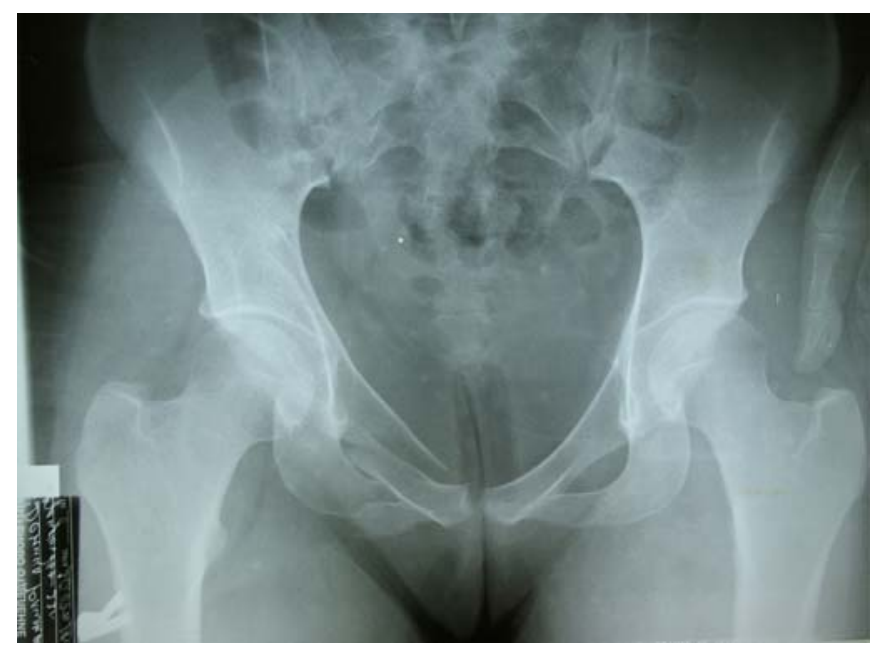

Fig. 3-a. Diagnostic X- ray Picture - AP

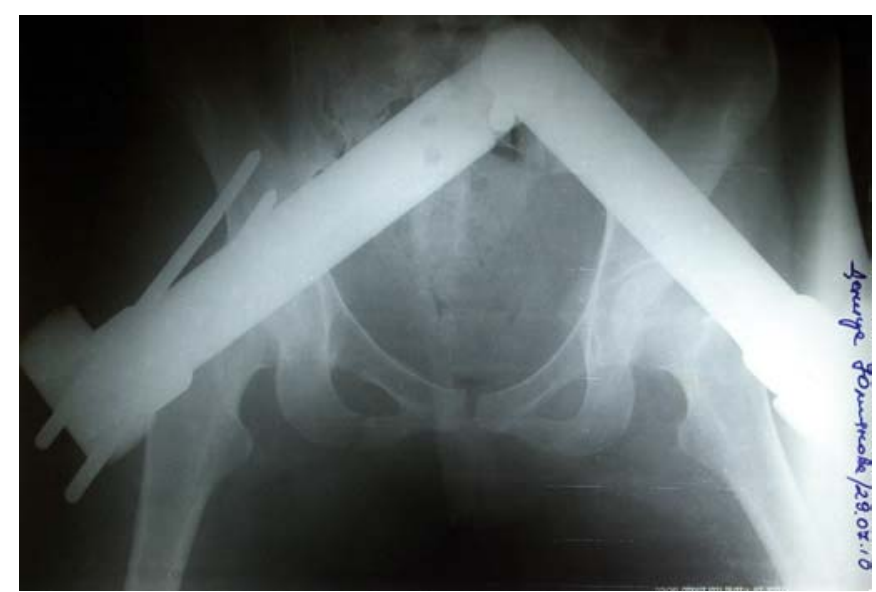

Fig. 3-b. Operative Control

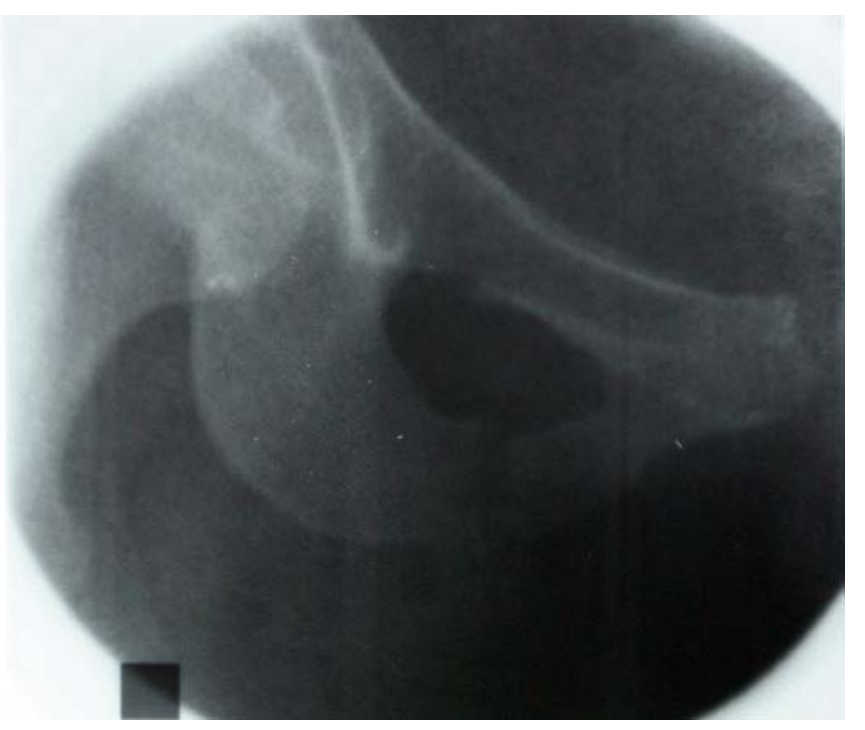

Fig. 3-c. Operative Control 


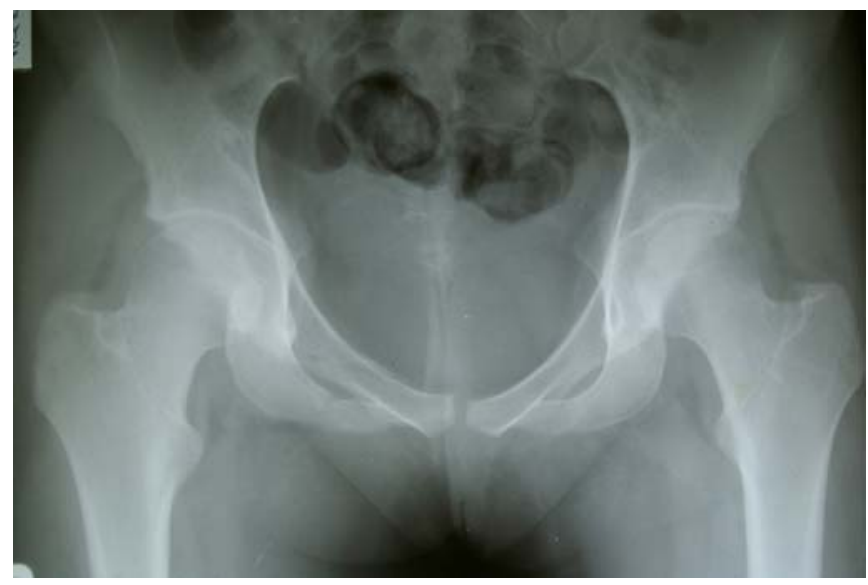

Fig. 3-d. After 18 months

\section{Case 3:}

I.P. - 33-year-old, after a road traffic accident, LCinjury, totally instable (osis pubis, osis sacri fracture)

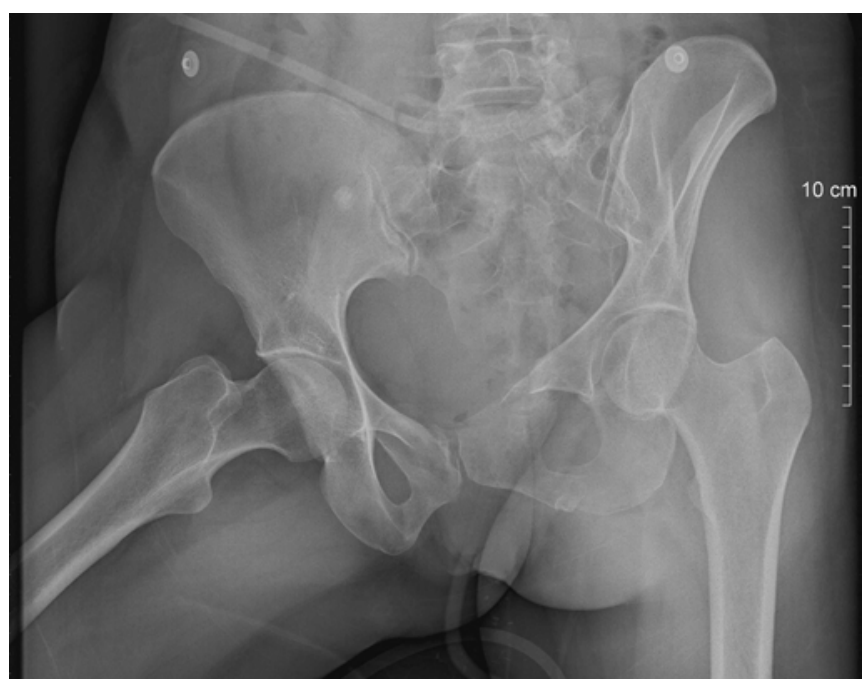

Fig. 4-a

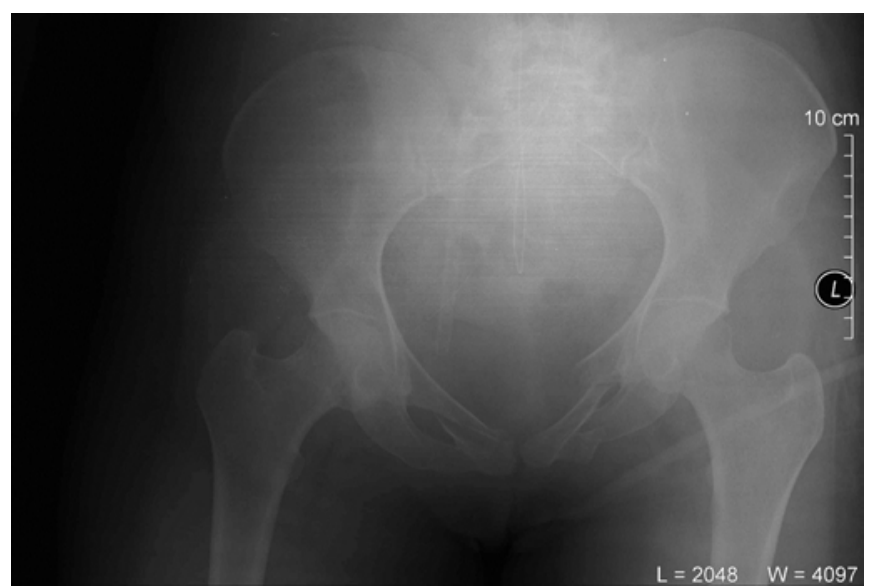

Fig. 4-b
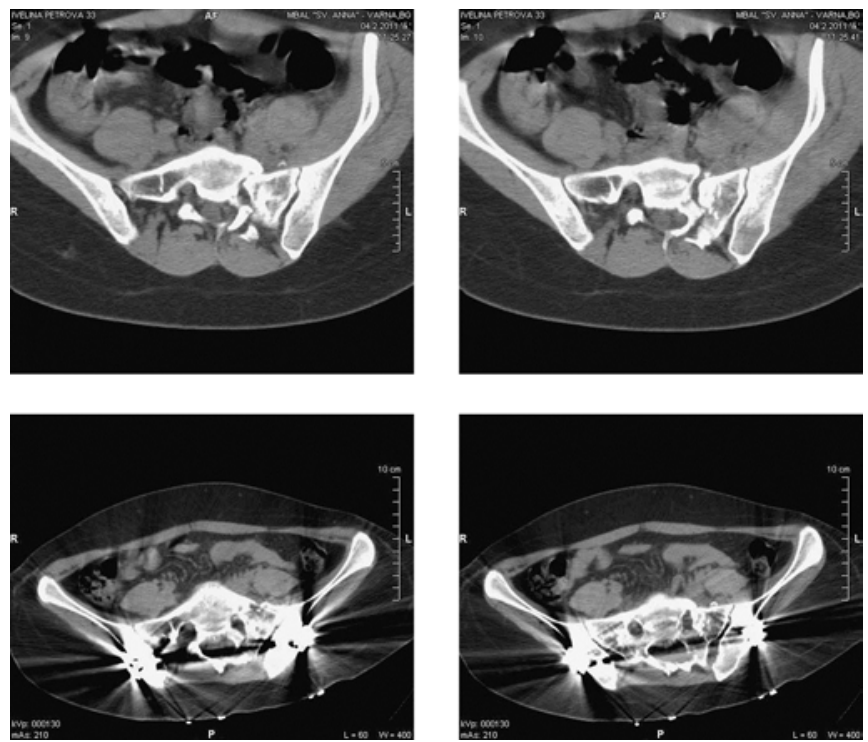

Fig. 4-c, 4-d, 4-e, 4-f

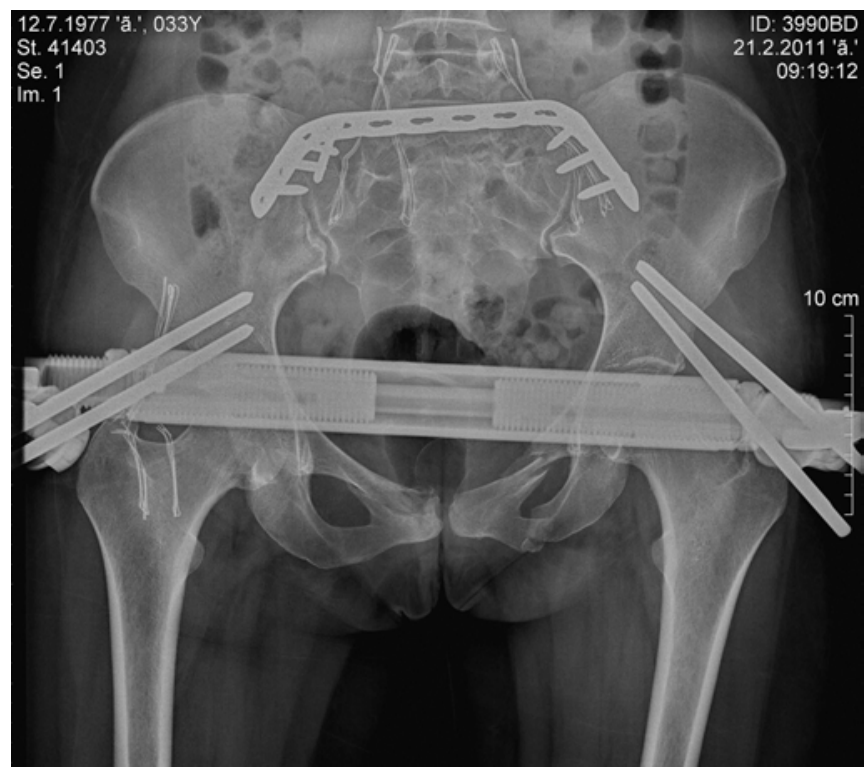

Fig. 4-g

\section{CONCLUSIONS:}

Due to the discomfort that a possible posterior external fixation may cause the patients, the reduction is supported with a U-shaped plate or "reverse" traverse. The anterior stabilization is maintained by an exterior supraacetabular fixation.

We recommend this technique (for its safety and excellent results) especially for women with a significant deformation of the pelvic ring, due to lateral compression, for tilt-fractures, and for compression fractures of the sacrum. 


\section{REFERENCES:}

1. Apostolov P, Jivkov M, Tilt-fractures of the pelvis - diagnosis and treatment, Bulgarian Orthopaedics and Traumatology, 2005; vol.42: 162-166

2. Bellabarba C, Ricci WM, Bolhofner BR. Distraction external fixation in lateral compression pelvic fractures. J Orthop
Trauma. 2000 Sep-Oct;14(7):475-82. [PubMed]

3. Tile M. Anatomy of the pelvic ring. In: Tile M, Helfet DL, Kellam JF, eds. Fractures of the Pelvis and Acetabulum, 3rd ed. Philadelphia, PA: Lippincott Williams \& Wilkins; 2003:12-21.
4. Burgess AR. External fixation in the multiply injured patient. Instr Course Lect. 1990;39:229-32. [PubMed] In: Green WB, ed. Instructional Course Lectures, The American Academy of Orthopedic Surgeons

Address for correspondence:

Pavlin Kirilov Apostolov

MBAL "St. Anna"- Varna, Clin. Orthopaedy and Traumatology

100, Tzar Osvoboditel Blvd., 9000 Varna, Bulgaria

Bulgaria, Varna, Mladost 142-9-4-194

E-mail: dr_apostolovo@yahoo.com.hk 